\title{
Busbar Configurations for HVDC Grids
}

\author{
E. Torres ${ }^{1}$, P. Eguia ${ }^{1}$, A. Iturregi ${ }^{2}$, O. Abarrategui ${ }^{2}$ and A. Etxegarai ${ }^{1}$ \\ ${ }^{1}$ Department of Electrical Engineering, Faculty of Engineering of Bilbao, UPV/EHU \\ Alameda de Urquijo s/n, 48013 Bilbao (Spain) \\ ${ }^{2}$ Department of Electrical Engineering, University College of Technical Mining and Civil Engineering, UPV/EHU \\ Rafael Moreno 'Pitxitxi' 2, 48013 Bilbao (Spain) \\ e-mail: esther.torres@ehu.eus
}

\begin{abstract}
The development of HVDC grids requires analyzing the configuration of DC busbars for the connection of converters and for meshing the grid, taking into account the specific characteristics of DC regarding fault clearance and current interruption. In principle, similar busbar topologies to those used in AC systems can be used. However, due to technical and economic considerations DC switchyards can be optimized by means of the combination of DC breakers of different technologies. This paper reviews the main characteristics of DC fault current, its interruption and the different technologies of DC circuit breakers, as well as proposals from manufacturers and researchers for the design and optimization of DC switchyards.
\end{abstract}

\section{Key words}

HVDC grid, busbar, DC breaker, grid topology.

\section{Introduction}

HVDC technology has been traditionally applied only when $\mathrm{AC}$ power transmission was not technically viable or was uneconomic and so, typical applications of HVDC have been cost-effective bulk power transmission over long distances as well as undersea transmission lines to avoid the negative effect derived from continuous charge and discharge of cable capacitance. However, nowadays there is a renewed interest in HVDC as the development of DC grids is considered key to make possible the expected development of the power system, which envisions a massive integration of renewable generation from far away offshore wind-farms or solar power plants to provide growing demand with environmentally friendly power.

Current HVDC schemes are point to point connections with converter stations at both ends, except for two multiterminal schemes in Italy and Canada [1]. Possible configurations for HVDC connections are asymmetrical monopoles, symmetrical monopoles and bipoles. In an asymmetrical monopole, a low voltage conductor earthed at one or both terminals is used as a return path, whereas two high voltage conductors with opposite polarity are used in symmetrical monopoles. In contrast, in bipolar configurations two converters in series are used at both ends, each of them connected between the positive or negative pole and the neutral point.

The development of a HVDC system can be based on the use of multiple point-to-point HVDC connections but, if the number of connections increases, it could be advisable to develop a multi-terminal meshed DC grid, named simply as DC grid in this paper. Fig. 1 shows a schematic view of both approaches where a dot represents a single converter. In the case of a DC grid not only a reduction in the number of converters is achieved, but also the power limitation in the nodes due to the converter stations is avoided, as power can flow freely through the DC grid to other nodes.

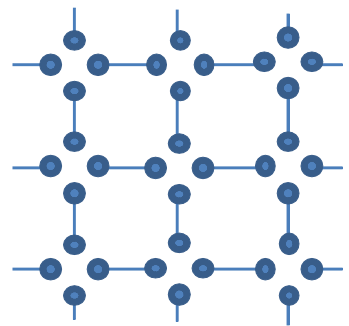

(a)

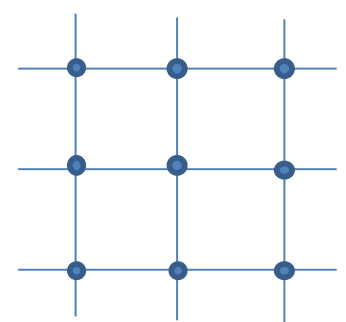

(b)
Fig. 1. Multi-Point to point HVDC system (a) and DC grid (b)

This way, DC grids can produce important savings. According to [1], a DC node with four DC links, as represented in Figure 1, would require 4 converters and a total of 24 valves in a point to point scheme, whereas in a meshed grid only one converter, 10 valves and 4 DC breakers would be necessary. The later design implies a saving of up to $50 \%$ in terms of installation and operation costs. Therefore, HVDC grids will require the development of DC switchyards where the connection of converter and line terminals can be accomplished.

In this paper, the main issues regarding the topology of DC switchyards of HVDC grids is reviewed, analyzing the differences with AC busbar topologies as well as the alternatives available to achieve a reliable and economic operation of DC grids. 


\section{DC busbars for DC grids}

DC switchyards allow the connection of AC/DC converters and DC circuits to the corresponding DC busbar by means of DC circuit breakers and/or DC switches that allow to modify the topology of the grid or to provide isolation in case of a fault. As in current AC grids, the reliability level of the DC grid will depend on the redundancy level of the busbars used for interconnecting the different converters and DC lines. The objective is to clear circuit and bus faults without interrupting the service.

In principle, the same busbar configurations as in $\mathrm{AC}$ power systems are possible in DC systems [2]:

- Single busbar

- Two busbars and two breakers

- Two busbars and one breaker

- Breaker and a half

For DC grid application, single busbars will only be used for radial connections. It is expected that busbars with redundancy will be used for meshed topologies, as the DC grid will be used for bulk power transmission and a high level of reliability will have to be assured.

However, the differences of $\mathrm{DC}$ in comparison to $\mathrm{AC}$ regarding fault clearance and current interruption can be taken into account in order to optimize DC busbar topologies for DC grids.

\section{A. DC fault current clearing}

One of the main technical challenges for the development of DC grids is the protection of the grid, as fault currents should be cleared with the minimum disturbance to the transmitted power [3]. In point-to-point HVDC schemes, it is usually acceptable to trip the AC circuit breakers of the converters, disconnecting the converters from the AC grid to clear the fault. Nevertheless, in a DC grid, tripping AC breakers to clear a DC fault may not be acceptable, as it may involve disconnecting a significant part of the system. Therefore, fault protection methods must be developed to only allow the disconnection of the part of the DC grid affected by the fault [4].

Besides, detection and elimination of faults must be faster in DC grids than in AC systems [2]. In AC systems the fault current is limited by the network impedance, which is highly inductive. Therefore, the rise time of the fault current is much lower than in DC systems and the time available for the detection and isolation of the fault is longer. In contrast, in a DC grid the fault current can rise to high levels much faster than in AC systems and the voltage drops spread out also much wider, because the DC line resistances are much lower than the $\mathrm{AC}$ line impedances.

In addition, when a fault happens in a DC line terminal close to a converter, the fault current supplied by the $\mathrm{AC} / \mathrm{DC}$ converter is larger than the fault current supplied from the other line end.
These issues can be analysed using the DC test system developed by CIGRE Study Committee B4 [5] and shown in Fig. 2. The system is composed by three VSCDC systems named DCS1, DCS2 y DCS3.

DCS1 is a 2-terminal symmetric monopole HVDC link $(+/-200 \mathrm{kV})$. It connects the offshore wind power plant at $\mathrm{C} 1$ to the onshore node A1 by a $200 \mathrm{~km}$ cable. At each line end there is an AC/DC converter with MMC topology, named $\mathrm{Cm}-\mathrm{A} 1$ and $\mathrm{Cm}-\mathrm{C} 1$ in the model.

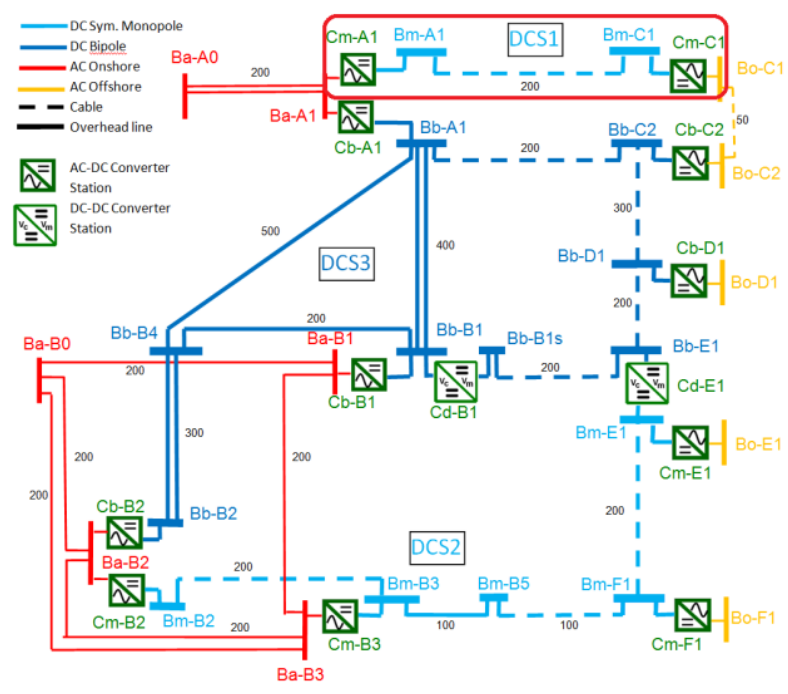

Fig. 2. CIGRE B4 DC Grid Test System [5]

Using the implementation of DCS1 model in PSCAD simulation software, a pole to pole fault with $200 \mathrm{~ms}$ duration has been analysed at each DC line terminal.

Fig. 3 shows the fault current supplied by each line terminal for a pole to pole fault at terminal Bm-A1. The current supplied from the faulted terminal (blue line) rises to its peak value in $15 \mathrm{~ms}$ and decays linearly during the fault. The current from the other line end (green line) is lower and decays exponentially.

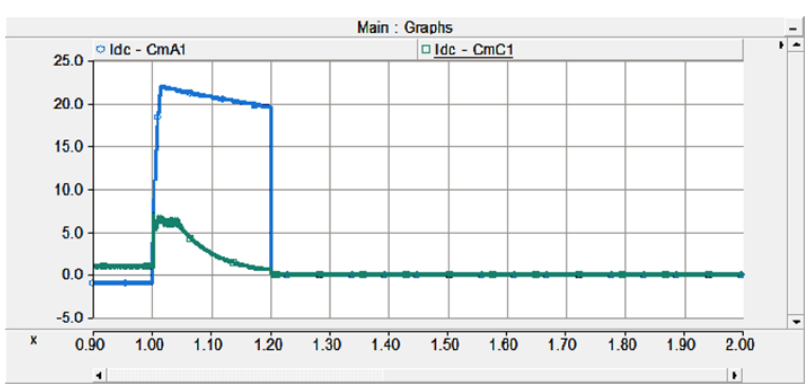

Fig. 3. DC fault current (kA) at each line terminal for a pole to pole fault at terminal Bm-A1

The same behaviour can be observed for a similar fault at the other line end. Fig. 4 shows the same fault currents for a $200 \mathrm{~ms}$ pole to pole fault at terminal $\mathrm{Bm}-\mathrm{C} 1$. The fault current supplied from the faulted line end (green line) rises to its peak value in $14.8 \mathrm{~ms}$ and decays linearly. The fault current from the other line end (blue line) is lower and decays exponentially. 


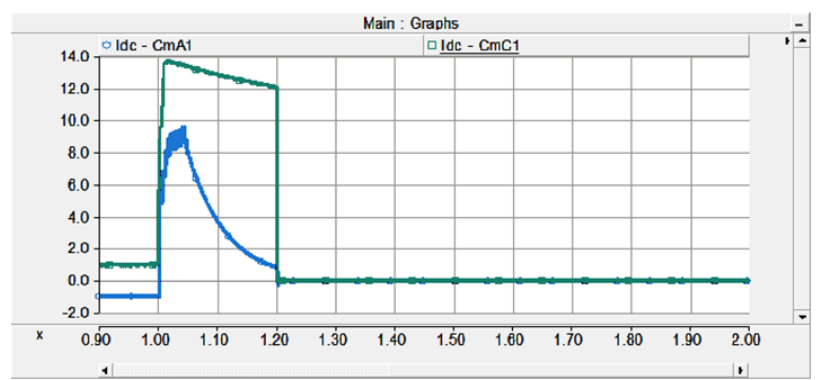

Fig. 4. DC fault current (kA) at each line terminal for a pole to pole fault at terminal $\mathrm{Bm}-\mathrm{C} 1$

From the previous example, it can be concluded that for a pole to pole fault at a DC line terminal, the fault current supplied from the faulted line end is larger than the current supplied from the other end and peaks in a shorter time. This characteristic behaviour can be used to optimize the configuration of the DC busbar, as shown in section 3 .

\section{B. DC circuit breakers}

In current HVDC applications, only transfer and load current switches are in use. HVDC breakers for interrupting short circuit currents are not commonly available and have very limited ratings [6]. Therefore, new HVDC breakers able to interrupt DC current faults must be developed.

AC current exhibits two natural zero crossings per cycle, which makes current interruption easier, as it can be achieved by simply separating the contacts. However, DC current has the disadvantage that there is no natural zero current crossings so a DC breaker must force current to zero to interrupt the current. It is also necessary to provide a means to dissipate the large amount of energy stored in the system inductances and to suppress overvoltage after current interruption [6].

Different interrupting methods have been proposed. They can be classified as follows [1], according to how the current zero condition is achieved:

- Inverse voltage generating method. The current is forced to zero by means of increasing the arc voltage to a higher value than system voltage.

- Current commutating method. Parallel paths are provided in the circuit breaker to commutate the current, so the energy stored in the circuit can be dissipated or a high-frequency oscillating current is obtained.

- Inverse current injecting method. A highfrequency inverse current is injected that interferes with the current to interrupt.

Using the previous techniques, DC circuit breakers can be classified as [7]:

- Mechanical (Fig. 5). They consist of a conventional AC breaker with a parallel resonant circuit to create a current zero crossing, being the operation speed in the order of tens of ms.

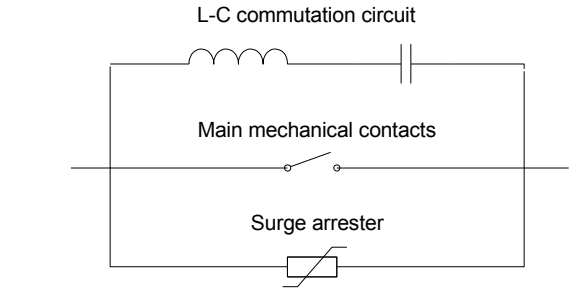

Fig. 5. Mechanical DC breaker (adapted from [8])

- Solid state (Fig. 6). They consist of several solid state switches in series, usually IGBTs, together with snubber circuits for voltage balancing. The operation speed is in the order of a few ms. A solid state breaker can only break current in one direction. In order to achieve a bidirectional device, two devices are needed, which increases the switch count and so, the device cost. Besides, a solid state breaker presents a permanent on resistance which causes larger losses than for a mechanical DC breaker.

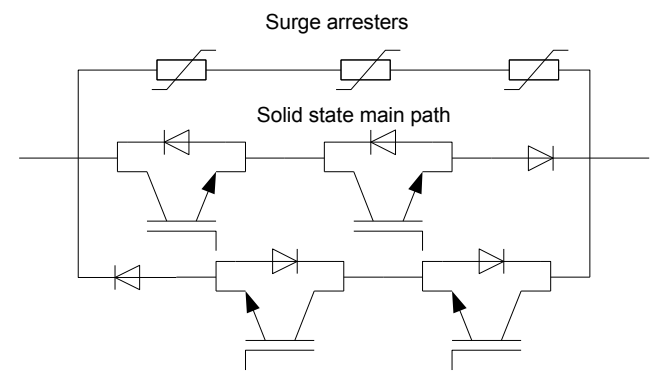

Fig. 6. Bidirectional solid state DC breaker (adapted from [9])

- Hybrid (Fig.7). It is a combination of a fast mechanical DC switch in parallel with a solid sate DC breaker. It achieves fast current interruption with low steady-state losses.

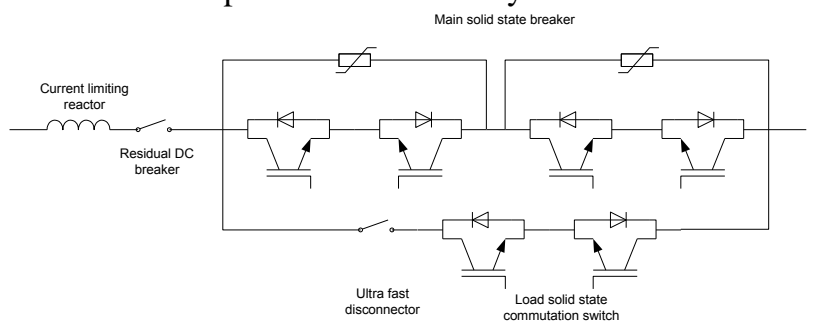

Fig. 7. Hybrid DC breaker (adapted from [10])

Mechanical DC breakers are relatively cheap but their operation speed and current breaking capacity is lower, which limits their application in DC grids based on Voltage Source Converters (VSC) with very limited over current withstand. In contrast, solid state and hybrid DC breakers are faster and so, more suitable for DC grid application.

Additionally, another solution under research for fast interruption of large DC currents is to use a fault current limiter device (FCL) in series with a mechanical DC breaker. When a fault appears, the FCL detects a sudden current increase and limits the current during several $\mathrm{ms}$ to a value that can be interrupted by a low speed mechanical DC breaker. 


\section{Optimisation of DC busbar configurations for DC grids}

DC breakers are still in development and their costs are expected to be much larger than for similar AC breakers, so there is room for optimisation of DC busbar topologies and some proposals have been made in order to reduce the overall cost of a DC grid.

In [11], a simplification of the DC breaker configuration is proposed, based on a combination of unidirectional and bidirectional solid state DC breakers to clear faults at any busbar and circuit of the arrangement, as an alternative to the use of bidirectional DC breakers at every location. Fig. 8 shows a schematic view of the application of this approach to a one and a half breaker switchyard.

Semiconductors of unidirectional DC breakers can be arranged to conduct towards or away the busbar while bidirectional DC breakers consist of two series unidirectional sections with semiconductors arranged to conduct in opposite directions.

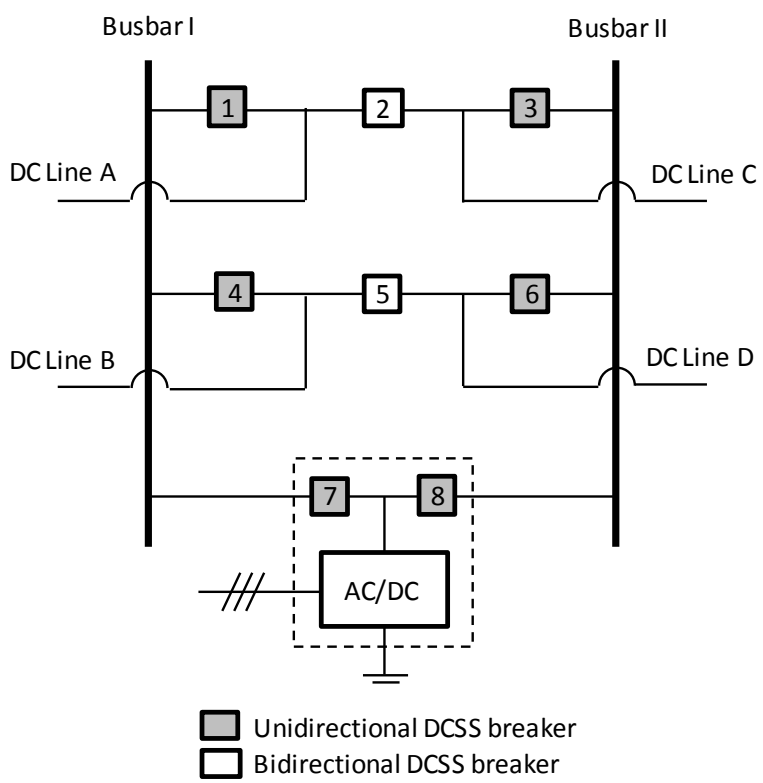

Fig. 8. DC busbar switchyard with unidirectional and bidirectional DC solid state breakers (DCSS)

In Fig. 8, if semiconductors of unidirectional breakers are arranged to conduct towards the busbar, a fault in Line A would require bidirectional breaker 2 and unidirectional breakers 4 and 7 to open in order to disconnect the other DC lines and the converter from the faulty line. After that, the DC line sided mechanical disconnectors of the breaker 1 can be opened and the unidirectional breakers 4 and 7 reclosed. In the case of a busbar fault all DC breakers connected to that busbar shall be opened.

Protection against internal line to ground faults of the unidirectional breaker 1 is also achieved by opening the breaker at the switchyard located at the other end of Line A as well as breakers 2, 4 and 7, before opening the disconnectors to isolate the faulty device. With this arrangement not only is reliability level properly guaranteed, but an important reduction in the number of switching devices is also achieved, as only $62.5 \%$ of the semiconductor switches is necessary in comparison to a similar configuration based only on bidirectional breakers. A two busbar is also considered in [11], leading to a saving in the number of switching devices equal to $25 \%$.

In [12], another modification of standard busbar arrangements is proposed to reduce the installation costs. In particular, the use of fast solid state DC breakers only in the connection of VSC terminals and slow mechanical DC breakers for DC lines is proposed. This simplification is based on the fact that the steady state DC fault current is supplied from the AC grid through VSC terminals while DC lines only supply transient DC current from the discharge of the line and cable capacitances.

As shown in the example of section 2, when the fault happens near the power source, the impedance will be low and the current will rapidly grow to a high value so fast clearing is essential. However, the early elimination of the current contribution from the local HVDC station removes the main fault contribution so the rise of the fault current at the DC switchyard is also limited. This provides a further cost reduction, as DC circuit breakers with lower speed and current breaking capability requirements can be used. In Fig. 9(a) and (b), an example of the application of this approach to a one and a half breaker switchyard is shown.

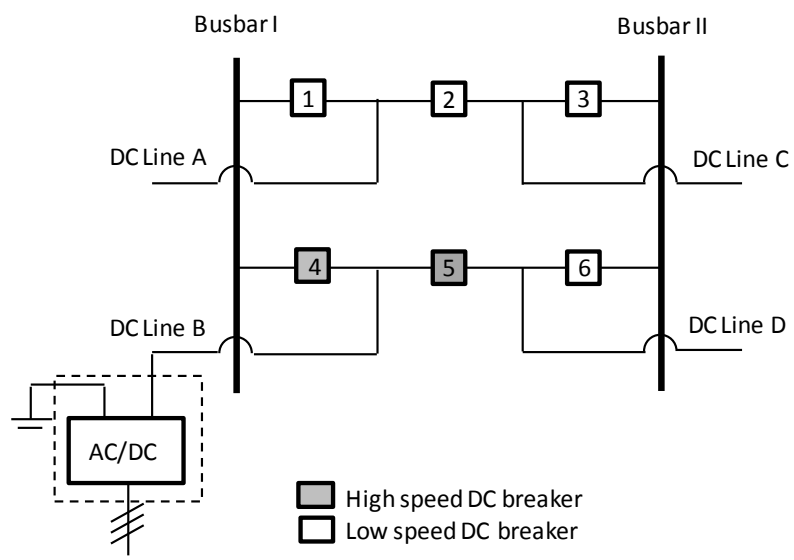

(a)

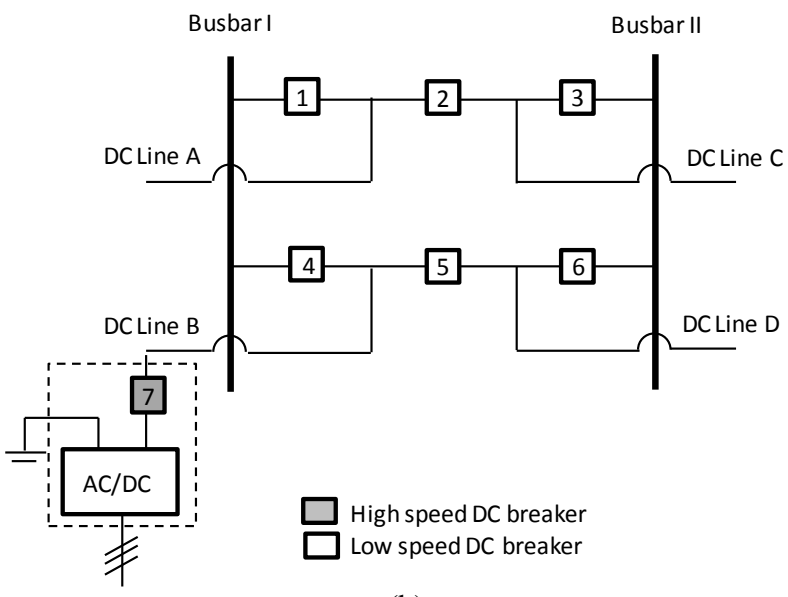

(b)

Fig. 9. DC busbar switchyard with fast semiconductor and slow mechanical DC breakers 
A fault at the local HVDC station would be cleared by fast semiconductor DC switchyard breakers 4 and 5 (Fig. 9(a)) or by the DC station fast breaker 7 (Fig. 9(b)), whereas a fault at a DC line interconnecting another HVDC station would be cleared by slower mechanical DC breakers connecting the line to the DC switchyard.

This approach can be applied to any busbar configuration, such as the so-called double busbar, ring busbar, etc. As proposed in [12], the interconnection of several DC switchyards comprising higher and lower speed DC breakers can be very useful in the development of a HVDC grid with lower costs compared to having DC switchyards where all DC breakers are fast breakers.

A variation of the optimization proposed in [12] consists in substituting the high speed DC breakers 4 and 5 in Fig. 9(a) or 7 in Fig. 9(b) by a FCL device in series with a low speed DC breaker. However, this solution is still at the design stage, as there are no FCL devices available for HVDC application.

\section{Conclusions}

The development of DC grids requires the use of busbar configurations with sufficient redundancy to achieve a level of reliability similar to or higher than for current HVAC networks.

This paper has analyzed the proposals for DC busbar configurations and the various optimizations that take advantage of the characteristics of DC faults in DC and different DC interruption technologies.

Although some prototypes are available, DC breakers still require further development to reach the levels of voltage and current breaking capacity necessary for application in a HVDC grid. Therefore, the use in future of a given busbar configuration or one of the proposed optimized configurations will depend on the development of the DC current interruption technology.

\section{Acknowledgement}

The authors thank the support from the Basque Government (projects ETORTEK IE14-389 and ELKARTEK HVDCLINK) and the University of the Basque Country UPV/EHU (project EHUA15/25).

\section{References}

[1] CIGRE WG B4.52, "HVDC Grid Feasibility Study", Brochure 533, April 2013.

[2] Van Hertem D., Ghandhari M., Curis J.B., Despouys O. Marzin A., "Protection requirements for a multi-terminal meshed DC grid", in Proc. Cigre Bologna Symposium, September 2011.

[3] Van Hertem D., Ghandari M., "Multi-terminal VSC HVDC for the European supergrid: Obstacles", Renewable and Sustainable Energy Reviews, Vol. 14, No 9, pp. 3156-3163, December 2010.

[4] Barker C.D., Whitehouse R.S., Adamczyk A.G., Boden M., "Designing fault tolerant HVDC networks with a limited need for HVDC circuit breaker operation", in Proc. CIGRE Session, August 2014.

[5] T.K. Vrana, Y. Yang, D. Jovcic, S. Dennetière, J. Jardini and H. Saad, "The CIGRE B4 DC Grid Test System". Available online: http://b4.cigre.org/content/download/34038/1483266/version/1/ file/CIGRE B4 DC Grid Test System FINAL corrected ver sion_with_Intro_V15.docx

[6] Franck C.M., "HVDC Circuit Breakers: A review identifying future research needs", IEEE Transactions on Power Delivery, Vol. 26, N 2, pp. 998-1007, April 2011.

[7] K. Sano, M. Takasaki, "A Surgeless Solid-State DC Circuit Breaker for Voltage-Source-Converter-Based HVDC Systems", IEEE Transactions on Industry Applications, Vol. 50, No. 4, pp. 2690-2699, July 2014.

[8] CIGRE JWG 13/14.08, "Circuit-breakers for meshed multiterminal HVDC systems", Brochure 114, June 1997.

[9] E. Kontos, R. Teixeira, S. Rodrigues and P. Bauer, "Impact of HVDC Transmission System Topology on Multiterminal DC Network Faults", IEEE Transactions on Power Delivery, Vol. 30, No. 2, pp. 844-852, April 2015.

[10] R. Derakhshanfar, T.U. Jonsson, U. Steiger and M. Habert, "Hybrid HVDC breaker - A solution for future HVDC systems", in Proc. CIGRE Session, August 2014.

[11] G. Asplund, J. Häfner, "High Voltage DC Switchyard With Semiconductor Switches", US Patent 2013/0050888 A1, Feb. 28, 2013.

[12] J. Häfner, B. Jacobson, T. Jonsson, K. Lindén, B. Berggren, "HVDC Switchyard and an HVDC Switchyard System”, US Patent 8803358 B2, Aug. 12, 2014. 